\title{
Editorial
}

\section{Why Music Educators Really Understand Skills}

The issue of knowledge and skills as competing factors in education has been considered in BJME editorials previously, notably 30(2) and 33(2) (Fautley \& Murphy, 2013, 2016). This is a matter which not only affects the English system specifically, however, as there are strains of it being felt in many jurisdictions throughout the world. It is worth revisiting in this editorial because of a number of elements of the ways in which conceptualisations of this dichotomy are influencing what is enacted in policy. This is having an impact at both the macro and micro levels in and between schools and education systems (Schmidt, 2017).

What is taking place in England in a rising number of instances is that schools, and schooling systems, are becoming increasingly vocal in their statements, and relentless pursuit, of what are often called 'knowledge-based curricula'. These institutions define knowledge almost entirely as being declarative knowledge, with facts being at the centre of these. Skills, as has been pointed out in previous editorials, are either downplayed or discredited. But this view of a narrow knowledge-based education system is predicated on constructs which we in music education have no problem reconciling. For example, here are two elements of learning which I have observed in school lessons:

1. Improvising on tuned percussion in the key of $\mathrm{F}$ major

2. The scale of $\mathrm{F}$ major uses the note $\mathrm{Bb}$

These are both legitimate ways of formulating learning. But in a knowledge-based curriculum, I hear teachers tell of how item 2 is prioritised over item 1 , as 2 is knowledge, and 1 is skill. But, they argue, 2 is needed in order to be able to do $1 ; 2$ involves remembering, 1 involves doing. And it is here that the quintessential nature of conceptualisations regarding skills in music education comes to the fore. The readership of the BJME will have no problem comprehending that 1 involves a number of complex factors, but for the non-core BJME readership let me spell some of these out. At its most basic, to play on a Glockenspiel involves precision of movement. The moment of sounding from the note-bar is at the point of the beat. This means that the movement of the beater (mallet) has to have started before the beat; it needs to be anticipated exactly so as to strike the note bar precisely on the beat. Playing notes out of time, behind the beat, as movement has started on the beat will be too late. This (to us) obviousness means that considerable anticipatory and experiential skill is involved in being able to achieve this. And herein lies the rub. We in music education really understand this. For us music educators, skills often also have a physicality, embodiment, or musculoskeletal component, in which feeling the music, its beat at the very basic level, involves more than simple recall. This distinguishes the skill of playing a musical instrument from, say, the skill of long division. Whilst long division is clearly important, it does not carry within it the same level of involvement, of embodiment and musculoskeletal involvement; and whilst I am sure that many children and young people do enjoy it, the visceral pleasure of music making is of a very different order. 
What this all means is that we music educators really understand skills. We know (knowledge - ironically) that skills are not only a vital part of music making, they are integral to what Swanwick (1999) referred to as teaching music musically. Indeed, there is a move afoot from the knowledge-based curriculum movement to teach music in a way that we might characterise as being non-musical, a step backwards towards the musicappreciation-as-compulsory-enjoyment and what-Beethoven-had-for-breakfast lessons of the past. These are lessons about music, not music lessons. I am sure it is possible construct maths lessons about long division without actually ever doing any sums, but this is not what our colleagues in the maths departments in schools and colleges would recognise.

So why is this sort of move towards non-musical music lessons even being considered? One of the reasons is to be found in the English education system's obsession with progress, and especially of measuring (or, rather, of trying to measure) it in each and every pupil in a school. Finn (2016) describes how this takes place in the English school system as involving a shift in the focus of attention:

... a concern for progress is bound up with modes of measuring, that is, producing, progress. This follows alongside the discursive shift from teaching being the proper focus of teacher's efforts to the issue of whether learning is actually taking place. In 'learner-centred' education, teachers are made responsible for producing learning that is, they are made responsible for producing a very specific form of enumerated progress, separated from class, ethnicity, gender and family structure and circumstance. (Finn, 2016, p. 36)

This seems to lie at the heart of the issue. Not just evidence of progress but evidence of the measurement of progress has to be produced, and, possibly unsurprisingly, this results in an application of Campbell's law (Campbell, 1976):

... achievement tests may well be valuable indicators of general school achievement under conditions of normal teaching aimed at general competence. But when test scores become the goal of the teaching process, they both lose their value as indicators of educational status and distort the educational process in undesirable ways.

In this case the measurement of progress has taken over as the goal of education, and it is clearly much, much easier to measure progress in knowledge of key signatures than in quality of improvisations. School management teams are desperate for data, and so the easiest route to data-production is followed, with the blessing of school leadership teams. This may well result in better, and more accurate measurement, but if what is being measured is not worth that much in the first place, it will be a pyrrhic victory. So let us hope that we can return to thinking about the musical nature of teaching and learning in music education.

Which takes us to the collection of articles in this current edition of the British Journal of Music Education. We begin by thinking about relationships between student identity and the assessment of group composing at school using an Activity Theory approach, written by Vicki Thorpe in New Zealand. Activity Theory is an emerging methodology in music education, and this represents a significant contribution to the field, as well as considering the important matters of identity and assessment. From this we move around the globe to Europe, where Sam de Boise writes about Gender Inequalities and Higher Music Education, 
and compares situations in the UK and in Sweden. Sam argues that 'Emancipatory, feminist notions of "freedom to choose" ... become co-opted by neoliberal rhetoric to mean "unlimited choice" without thinking about how those choices are socially influenced ... ' This provides much food for thought for those of us working in HE in music education.

We stay in the UK for our next article, where Mark Rimmer discusses children's valuations of a Sistema-inspired initiative. An increasingly complicated picture is emerging of El Sistema and related initiatives, and Rimmer's description contains some worrying observations: ' . . . the picture of In Harmony which emerges is one of an initiative which, despite its appeal to some children, generally fails to connect meaningfully with many children's own musical interests, passions or motivations ... '; interesting. We stay in Europe, but move across the channel to Belgium for our next piece, an investigation by Jacob M. Dakon and Elene Cloete concerning social interaction through eclectic music learning practices, which they define as ' ... a musical environment that uses a blend of informal and formal learning practices'. There is much discussion concerning formal, informal, and non-formal learning in music education currently, and this is another useful contribution to the literature.

We move around the world again for our next piece, wherein Jodie L. Martin from Sydney considers the selection and arrangement of notation in jazz students' written texts. The issue of notation is a permanent 'hot potato' in music education, and has been covered in these editorials before, including most recently in issue 34(2) (Fautley, 2017). Here we are thinking about the ways in which notation is used, and this challenges us all to think about what we and our students do with it. As Martin notes,' ... music notation varies according to the purpose it is used for.' A though-provoking observation which troubles simplistic acceptances.

Finally in this issue we skip around the globe once more, this time to Norway, where Anne Kristine Wallace Turøy considers issues of singing in a kindergarten teacher program at a Norwegian university college. She finds a range of fascinating issues concerning singing, both in terms of approach and attitude, but also of self-efficacy, and, as she puts it 'authentic experiences of mastery'.

Yet again we have what is to be hoped is an interesting and eclectic range of studies from around the world in music education. As always it is to be hoped that the authentic voices of the authors, in all their different contexts, shine through these pieces. I hope you enjoy them, and that they give you pause for thought yourself in your own day-to-day engagement with music education.

MARTIN FAUTLEY

BJME Editor

\section{References}

FAUTLEY, M. \& MURPHY, R. (2013). Editorial. British Journal of Music Education, 30(2), 157-159. doi:10.1017/S0265051713000168

FAUTLEY, M. \& MURPHY, R. (2016). The nature of music itself, and the knowledge versus skills debate in music education. British Journal of Music Education, 33(2), 129-132. doi:10.1017/ S026505171600022X 
FAUTLEY, M. (2017). 'Notation and Music Education,' British Journal of Music Education. Cambridge University Press, 34( 2), pp. 123-126. doi: 10.1017/S0265051717000031.

Campbell, D. (1976). Assessing the Impact of Planned Social Change. Social Research and Public Policies: The Dartmouth/ OECD Conference. G. Lyons. Hanover, NH, Public Affairs Center, Dartmouth College. Finn, M. (2016). "Atmospheres of progress in a data-based school." cultural geographies 23(1): 29-49.

Schmidt, P. K. (2017). Why Policy Matters. Policy and the Political Life of Music Education. P. K. Schmidt and R. Colwell. New York, Oxford University Press: 11-36.

Swanwick, K. (1999). Teaching music musically. London, Routledge. 